\title{
Challenges to Integrating Pharmacogenetic Testing into Medication Therapy Management
}

\author{
Susanne B. Haga, PhD; Nancy M. Allen LaPointe, PharmD; and Jivan Moaddeb, PharmD
}

\begin{abstract}
SUMMARY
Some have proposed the integration of pharmacogenetic (PGX) testing into medication therapy management (MTM) to enable further refinement of treatments to reduce risk of adverse responses and improve efficacy. PGx testing involves the analysis of genetic variants associated with therapeutic or adverse response and may be useful in enhancing the ability to identify ineffective and/or harmful drugs or drug combinations. This "enhanced" MTM might also reduce patient concerns about side effects and increase confidence that the medication is effective, addressing 2 key factors that impact patient adherence: concern and necessity. However, the feasibility and effectiveness of the integration of PGx testing into MTM in clinical practice has not yet been determined. In this commentary, we consider some of the challenges to the integration and delivery of PGx testing in MTM services.
\end{abstract}

J Manag Care Spec Pharm. 2015;21(4):346-52

Copyright $\odot 2015$, Academy of Managed Care Pharmacy. All rights reserved.

$\mathrm{M}$ edication therapy management (MTM) and comprehensive medication reviews (CMR) have been shown effective in reducing inappropriate medication use, adverse events due to drug-drug interactions, and medication nonadherence. ${ }^{1-3}$ Pharmacist review of a patient's medication regimen, including indications for the medications, adverse event profile, and pharmacokinetic and pharmacodynamic properties, may identify ineffective and/or harmful drugs and drug combinations that can be changed and lead to improved health outcomes. ${ }^{3}$ Some have proposed the integration of pharmacogenetic (PGX) testing into MTM to enable further refinement of treatments to reduce risk of adverse responses and improve efficacy. ${ }^{4-7} \mathrm{PGx}$ testing involves the analysis of genetic variants associated with therapeutic or adverse response and may be useful in enhancing the ability to identify potentially ineffective and/or harmful drugs or drug combinations. This "enhanced" MTM might also reduce patient concerns about side effects and increase confidence that the medication is effective, addressing 2 key factors that impact patient adherence: concern and necessity. ${ }^{8}$ However, the feasibility and effectiveness of the integration of PGx testing into MTM in clinical practice has not yet been determined. In this commentary, we consider some of the potential benefits and challenges to the integration and delivery of PGx testing in MTM services.

\section{Overview of MTM}

As the safe and effective self-management of medications has become increasingly recognized as a key component to improving health, MTM services have transitioned from primarily patient education and counseling to systematic and coordinated processes for comprehensive medication management. ${ }^{9}$ Patients with chronic medical conditions likely have numerous health care providers, and as a result, multiple drugs may inadvertently be prescribed within the same medication classes or that may interact with each other, leading to increased risk of adverse events, failure to achieve therapeutic goals, discontinuation of medications, or reduced quality of life. Effective MTM aims to reconcile medication discrepancies and improve medication management.

Although practices can vary, MTM services should include 5 core elements: (1) medication therapy review, (2) personal medication record, (3) medication-related action plan, (4) intervention and/or referral, and (5) documentation and followup. ${ }^{10,11}$ Typically conducted by a pharmacist, MTM can serve as an educational tool for physicians and patients and provide a personalized strategy for patients to improve adherence with their medications, given their personal, economic, or other challenges with medication self-management. If modifications to a patient's current drug regimen are warranted, the pharmacist can also act as a liaison with the prescriber on behalf of the patient.

In 2003, the U.S. Medicare Prescription Drug, Improvement, and Modernization Act established a prescription drug benefit (Part D) that included a requirement for participating health plans to offer MTM services to eligible patients beginning in 2006. ${ }^{12}$ Part D enrollees who had multiple chronic diseases, taking multiple Part D drugs, and likely to exceed $\$ 3,144$ in annual costs (threshold for 2013) for covered Part D drugs (§423.153[d][1]) were considered eligible for these MTM services. However, eligible enrollees in many plans initially had to opt in to receive the MTM services, resulting in a small proportion of eligible patients receiving these services on prescription medications. ${ }^{13}$ This provision has now been changed so that eligible enrollees are offered MTM services unless they opt out with the hope that a greater proportion of patients will receive these services. As of 2013, there were 645 active Part D contracts with an approved MTM program. ${ }^{14}$ In addition, several state Medicaid plans and private, non-Medicare health plans provide access to and payment for MTM services. 
TABLE 1 Summary of Potential Challenges to Provision of MTM+PGx Testing Service by Community Pharmacists

1. Timing of and Access to PGx Testing

- Timing of PGx testing for making optimal drug decisions

- Access to PGx test results done in various clinical care settings

- Ability of pharmacists to order PGx testing

2. Extended MTM Sessions

- Pharmacist time constraints in community practice

- Uncertain added time needed for initial session, and follow-up session needed to introduce testing/discuss test results

- Uncertain feasibility of discussing PGx testing by phone versus face to face 3. Information Technology

- Limited access to patient's electronic health record

- Need to integrate PGx test information into health technology tools for MTM

4. Training and Workforce

- Limited PGx education in pharmacy curriculum

- Need for continuing education as PGx field grows

\section{Setting Standards}

- Development of standards for integrating PGx testing into MTM practice to provide consistent and documentable added value

- Consideration of pharmacist liability

\section{Reimbursement}

- Obtaining adequate reimbursement for MTM plus PGx testing service

MTM= medication management therapy; $P G x=$ pharmacogenetic.

\section{PGx Testing}

PGx testing for patients' genetic likelihood for an adverse response or to determine suitability for a targeted drug is at the forefront of the personalized medicine movement and is gradually moving from specialty medications (e.g., oncology) to more broadly prescribed medications (e.g., codeine, statins, or warfarin). To date, the drug labels of 137 medications include PGx-related information, and it has been estimated that 16\% of medications prescribed in primary care are impacted by PGx variants. ${ }^{15,16}$ Knowledge of a patient's genetic predisposition for an adverse response or therapeutic response can augment current clinical predictors to improve drug selection and response at the time of prescribing. For example, testing for HLA-B*57:01 is currently recommended to identify patients at risk of experiencing hypersensitivity reactions linked to abacavir. ${ }^{17-19}$ The U.S. Food and Drug Administration has issued warnings about potential codeine toxicity leading to adverse events or even death in those with a genetic variant of the CYP2D6 gene, resulting in very rapid and complete conversion of codeine into morphine in children and nursing mothers. ${ }^{20-22}$ The utility and integration of PGx information for other medications are still actively under investigation. For example, use of CYP2C9/VKORCl testing to inform warfarin dosing is currently under investigation for its usefulness in clinical settings to achieving international normalized ratio (INR) goals and reducing potential adverse events associated with out-of-range INRs. ${ }^{23-25}$
At this time, the delivery model of PGx testing is unclear, with different approaches currently under investigation. ${ }^{26-28}$ In general, PGx tests can be ordered at the time a medication is prescribed or preemptively for anticipated future treatment. ${ }^{27}$ Health professionals involved in the delivery of PGx testing may include the laboratorian, prescriber, pharmacist, and potentially a genetic counselor. With development of new and cheaper testing technologies, it is possible that a patient's genetic predisposition for a panel of drugs will be ascertained through a single test and results consulted as new medications are prescribed. . $^{29,30}$

\section{Challenges to Integrating PGx into MTM Services}

The addition of PGx testing to current MTM services would align well with the goals of MTM and fit within the scope of information discussed and reviewed between the patient and MTM provider. However, given barriers to the provision of current MTM services, it is important to consider the feasibility of adding this new element. In particular, the successful integration of PGx into MTM services likely faces multiple challenges at the health system, provider, and patient levels. Our discussion will primarily focus on challenges to the integration of PGx testing into MTM from the health system and pharmacist perspectives. We recognize that the extent and scope of some of these challenges may be heavily impacted by the type of health system (e.g., integrated vs. nonintegrated) and the extent to which pharmacists are utilized or valued in the broader health care system. In the following sections, we identify and discuss 6 potential challenges to the integration of PGx testing into MTM services in the U.S. health care environment (Table 1). These challenges were identified from a review of experiences encountered by early physician adopters and prospective users of PGx testing in the implementation of MTM and other pharmacy services. ${ }^{31,32}$ This list is likely not comprehensive, and new issues may be identified as more pharmacies begin to offer this service. We provide a general overview of the challenges rather than attempt to delineate challenges in different types of health care systems.

\section{Timing of and Access to PGx Testing}

Pharmacists may provide MTM services in a range of settings, most commonly in a hospital, outpatient clinic, or community pharmacy setting. ${ }^{33}$ As a result, each setting may present different challenges in integrating PGx testing into MTM services. Since the majority of MTM services are currently delivered by community pharmacists or clinic-based pharmacists, we will limit most of our discussion to these settings.

As mentioned previously, PGx tests may be ordered at the time a drug is prescribed or preemptively when the patient is healthy and stored for future use. Regardless of when the test is ordered, a clinic-based pharmacist would likely have the most rapid and convenient access to the test results and the patient's 
complete medical record. In contrast, a community pharmacist would have to rely on the patient to inform the pharmacist of the test result or obtain a copy of the results from the patient or physician. However, patient recall of PGx test results may be challenging for some, given the novelty of testing and unfamiliarity with such terms as "extensive metabolizer" or such test outcomes as "genotype." Acquiring a copy of the report from patients or providers may also be challenging, since patients may not have been given a written report that they can share, and physicians may be difficult to contact and reluctant to share laboratory reports with community pharmacists. A health information exchange (HIE) may be a feasible strategy for sharing test results among providers, including pharmacists, and could reduce duplicate testing by multiple providers, although a minority of states do not allow clinical laboratory results to be returned to a pharmacist. ${ }^{34-36}$ Although patients are generally supportive of HIE, some have expressed concerns about their privacy and the security of the HIE. ${ }^{37,38}$

Alternatively, clinic-based pharmacists could order PGx tests through collaborative practice agreements (CPAs), also known as collaborative drug therapy management. CPAs enable pharmacists to provide a variety of services in collaboration with other health providers (typically physicians) and may allow pharmacists to order PGx testing rather than depending on physician providers. Most states have enacted legislation permitting pharmacists to provide a range of drug therapy management services through CPAs, although the scope varies from state to state..$^{39,40}$ In 2013, 31 states permitted pharmacists to order clinical laboratory tests under a $\mathrm{CPA} .{ }^{41}$ In some cases, credentialing may be required; for example, only pharmacists certified as diabetes educators (e.g., via career development events such as continuing education) can order point-of-care tests. ${ }^{42}$

\section{Extended MTM Sessions}

A typical initial MTM session may last between 30 minutes to 1 hour, with follow-up appointments as necessary., ${ }^{3,43,44}$ If the pharmacist recommends PGx testing during the MTM, additional time will be needed to introduce PGx testing to the patient and discuss the purpose of the test, risks, and limitations and alternatives. In addition, a follow-up visit will be necessary to review the PGx results and their significance for the patient's drug therapy. While care may be improved for some patients with the inclusion of PGx testing, the additional time required to provide this service may result in a relative reduction in other MTM services. Even without PGx testing, it has been recognized that expanded patient eligibility for MTM consultations warrants additional service delivery options to address potential workforce shortages in some geographic areas. The National Committee for Quality Assurance recommended that the 2006 Sound Medication Therapy Management Programs (Version 1.0) revise its position that the preferred delivery MTM model be face to face. ${ }^{45}$ In 2013, 92\% of Part
D programs offered CMR consultation by phone; $42 \%$ also offered in-person consultations (up from 28\% in 2012); and $16 \%$ of programs offered CMR consultations through telehealth (up from 1\% in 2012). ${ }^{14}$ Several studies have demonstrated the effectiveness of phone MTM in addressing medication-related issues and patient satisfaction. ${ }^{46-49}$ However, it is unclear whether MTM plus PGx testing can be fully delivered via telehealth, given the amount of new and potentially complex information that would be discussed.

\section{Information Technology}

The storage and portability of a patient's PGx results will impact level of utilization. Information technology (IT) can greatly enable rapid access to a patient's prescription history and clinical test results. ${ }^{50} \mathrm{~A}$ clinic-based pharmacist, as previously described, could have access to PGx results through the clinic or health system's electronic health record. Likewise, MTM services could be documented in the electronic health record, and recommendations based on the test results could also be contained within the electronic health record. However, the clinic-based pharmacist would not likely have access or would have limited access to data on actual prescriptions filled or PGx tests ordered outside of his or her health system, except in a very small number of locations where these data might be accessible through an HIE.

Community pharmacists usually do not have access to a health system's electronic health record. Instead, community pharmacists often have a local (or pharmacy chain-specific) IT system focused on prescription fills with a separate IT platform for MTM services. The prescription database and MTM application can be locally integrated in order to facilitate completion of a medication reconciliation process that uses health plan prescription data and local pharmacy prescription data, especially for patients that use multiple pharmacies for their prescription medications. Currently, health IT tools for MTM services are primarily used to facilitate identification of patients eligible for reimbursable MTM services, complete medication reconciliation, and process reimbursement for pharmacists' MTM services. ${ }^{51}$ PGx test results obtained from the patient or provider could be manually entered into most of the MTM systems; however, access to these data by pharmacists in other locations may be nonexistent or very limited. Alternately, if testing is ordered by a pharmacist in the community setting, storage of the result in the community pharmacy database is also possible, since community pharmacists already have experience storing other lab results for drugs, such as clozapine. Therefore, a similar record of PGx results could be established and accessed for each new prescription. However, this also limits utilization of the PGx test results to that particular pharmacy. This discontinuity of care may particularly affect patients that obtain prescription drugs from multiple pharmacies for various reasons (cost, type of insurance, 
convenience) ${ }^{52}$ In addition, the lack of connectivity of the prescriber with these IT systems impacts continuity of care.

In addition, even if pharmacists had access to PGx results, clinical decision supports (CDS) may be needed to promote appropriate interpretation and utilization of results. Some CDS tools have been developed to assist physicians in considering testing or dosing/drug selection based on test results. ${ }^{28,53}$ To our knowledge, no similar CDS has been explored for pharmacists.

\section{Training and Workforce}

In 2012, approximately 286,000 pharmacists were estimated to be practicing, primarily in community pharmacies (43\%) and hospitals (23\%). ${ }^{54}$ Likelihood and interest in providing MTM services is predicted by pharmacist training and comfort level. ${ }^{55}$ The Accreditation Council for Pharmacy Education currently requires colleges and schools of pharmacy to provide basic MTM training. ${ }^{56}$ To fulfill this requirement, a range of training programs for MTM have been developed and implemented in pharmacy schools and continuing education programs. ${ }^{57-59}$ If pharmacists are ordering lab tests, they will also require additional training on communicating test results. One of the issues raised by pharmacists with new testing programs, such as HIV testing, are discomfort with communicating positive results. ${ }^{60}$

The delivery of PGx testing as part of an MTM service will require additional training for pharmacists. Currently, pharmacists report low knowledge and confidence in using PGx information for adjusting dose or drug selection. ${ }^{61,62}$ Several professional pharmacy organizations have called for the addition of PGx material into pharmacy curricula, and schools have positively responded, exploring numerous approaches. ${ }^{63-66}$ For practicing pharmacists, continuing education will help promote awareness of PGx, but more intensive training may be required if pharmacists offer PGx testing given the complexity of the material. ${ }^{67}$ Since decisions regarding changes to prescriptions must be approved by the prescriber, physicians, physician assistants, and nurse practitioners must also be knowledgeable to understand the PGx-guided recommendations to act appropriately. Physicians have reported low knowledge about PGx and are likely to have had limited exposure in medical schools. ${ }^{68-71}$ Several professional nursing organizations have recommended PGx content in nursing programs and genetics core competencies recommendations, although more effort is still needed to implement these recommendations into nursing programs. ${ }^{72-75}$

\section{Setting Standards}

Just as standards have been developed for MTM services in general, it will also be important to set standards for integrating PGx testing into MTM practice. In particular, given the relative novelty of PGx testing, it will be important to define what information should be delivered prior to testing and how to communicate the test results effectively and efficiently during the MTM session. Several factors may impact patientprovider communication about PGx testing, including provider knowledge, time, and patient interest. Since the genetics of drug response may be unfamiliar to patients, we suggest that a standardized teaching approach may be warranted to ensure that sufficient information is clearly presented to enhance patient understanding.

In addition, with the pharmacist's expanded role in interpreting and communicating PGx test results with patients and other providers, pharmacist liability would need to be addressed, since this expansion of current MTM services may be viewed as a potentially higher risk activity in our litigious society. Some have discussed the potential for liability and its potential adverse impact on provider behaviors regarding PGx testing. ${ }^{76,77}$ When multiple providers are involved in treatment decisions, pharmacist liability appears to be limited to medication dispensation. ${ }^{78}$ However, courts have begun to recognize the broader roles of pharmacists beyond dispensation and have applied a "reasonable professional" standard. ${ }^{79}$ Correspondence with the prescriber and patient are important elements in reducing liability, and a copy of the medication-related action plan, including the PGx test results (or summary for patients), should be shared with both parties. ${ }^{80}$ If a pharmacist has knowledge of a pateint's PGx test results, he or she may have a duty to warn patients of potential risks for current and future medications. ${ }^{81}$

\section{Reimbursement}

Another barrier to the provision of MTM services is reimbursement. ${ }^{82-84}$ Depending on the setting, pharmacist billing can vary, and new models continue to be explored. ${ }^{33,85,86}$ For example, in ambulatory care clinics, billing for pharmacist MTM services may be submitted as incident-to-physician care charges. ${ }^{87,88}$ With the establishment of pharmacists' Current Procedural Terminology billing codes (CPT codes 99605, 99606, and 99607), pharmacists may also directly bill for services. The variability in payer fee schedules and actual reimbursement rates further add to pharmacists' concerns about appropriate reimbursement for MTM services. ${ }^{89}$ The current confusion regarding billing codes and additional time required to complete documentation and billing indicate pharmacists need for additional support to obtain reimbursement. ${ }^{84,90}$ Indeed, a survey conducted in 2011 found that a substantial proportion of pharmacists reported not billing for MTM services. ${ }^{33,91}$ Others believe that Medicare Part D reimbursement is too low for pharmacy services including MTM. ${ }^{92}$ The inclusion of PGx testing into MTM with the anticipated additional time needed to discuss testing, collect and ship the sample, recontact the patient, and consult with the prescriber may further complicate reimbursement, since pharmacist CPT codes do not account for the complexity of MTM service and can only be used for in-person MTM. 


\section{Conclusions}

The growth in PGx research and the readily available means for conducting PGx testing in nontraditional settings provide patients and clinicians with new ways to manage medications. Pharmacists are uniquely trained in using in-depth knowledge of drugs and their properties to safely and effectively select and manage complex medication regimen. PGx testing can provide a new level of detail for potentially even better drug selection and management decisions. Pharmacist-delivered services, especially in community practice settings, continue to evolve to meet the demand from patients, payors, and other health care providers to improve medication management, including standardization and enhancements in MTM services. Now may be an opportune time to consider the feasibility of integrating PGx testing into MTM and to establish a niche for pharmacists in the personalized medicine movement.

As with any new service, the integration of PGx testing into MTM conducted by pharmacists faces several challenges. We have explored some of those challenges to stimulate discussion on potential next steps. Agreement from multiple stakeholders on the feasibility and value of this service, tested and proven models for implementation and dissemination, and an established business case are needed to advance this potential new method of medication management. This will likely require new partnerships between pharmacists and physician groups, diagnostic laboratories, and software vendors and engagement of professional societies and/or consortium of pharmacies to develop this potential new opportunity.

Despite the challenges, we see that community pharmacists are uniquely poised, with respect to their drug expertise, frequent interaction with patients, and interface between prescribers and patients, to play a key role in delivering PGx testing. We believe that patient engagement through a service such as MTM will be necessary, particularly during the early stages of implementation of PGx testing in general, to increase patient familiarity with testing and understanding of the results for current and future medication needs. Since additional tests may be performed for a given patient, the level of engagement needed may be less. As the practice of MTM and PGx testing matures, early integration of these 2 tools may benefit all stakeholders.

\section{Authors}

SUSANNE B. HAGA, PhD, is Associate Professor, and JIVAN MOADDEB, PharmD, is Clinical Pharmacist, Center for Applied Genomics and Precision Medicine, Duke University School of Medicine, Durham, North Carolina. NANCY M. ALLEN LAPOINTE, PharmD, is Associate Professor of Medicine, Duke Clinical Research Institute, Duke University, Durham, North Carolina.

AUTHOR CORRESPONDENCE: Susanne B. Haga, PhD, Center for Applied Genomics and Precision Medicine, Duke University School of Medicine, 304 Research Dr., Box 90141, Durham, NC 27708.

E-mail: susanne.haga@duke.edu.

\section{DISCLOSURES}

This study was funded by the Duke Center for Applied Genomics and Precision Medicine and by the National Institutes of Health (grant no. R01GM081416a).

Study concept and design were contributed primarily by Haga, along with LaPointe and Moaddeb. Data collection, analysis, and manuscript revision were performed by Haga, LaPointe, and Moaddeb. The manuscript was written primarily by Haga, along with LaPointe and Moaddeb.

\section{REFERENCES}

1. DiMatteo MR, Giordani PJ, Lepper HS, Croghan TW. Patient adherence and medical treatment outcomes: a meta-analysis. Med Care. 2002;40(9):794-811.

2. Pellegrino AN, Martin MT, Tilton JJ, Touchette DR. Medication therapy management services: definitions and outcomes. Drugs. 2009;69(4):393-406.

3. Ramalho de Oliveira D, Brummel AR, Miller DB. Medication therapy management: 10 years of experience in a large integrated health care system. J Manag Care Pharm. 2010;16(3):185-95. Available at: http://www.amcp.org/ data/jmcp/185-195.pdf.

4. Reiss SM; American Pharmacists Association. Integrating pharmacogenomics into pharmacy practice via medication therapy management. J Am Pharm Assoc (2003). 2011;51(6):e64-74.

5. Shaw L, Burckhard G. Therapeutic drug monitoring and pharmacogenetics interface considerations. In: Valdes R, Payne DA, Linder MW, eds. Laboratory Medicine Practice Guidelines: Guidelines and Recommendations for Laboratory Analysis and Application of Pharmacogenetics to Clinical Practice. Washington, DC: National Academy of Clinical Biochemistry; 2010:29-34.

6. Gervasini G, Benitez J, Carrillo JA. Pharmacogenetic testing and therapeutic drug monitoring are complementary tools for optimal individualization of drug therapy. Eur J Clin Pharmacol. 2010;66(8):755-74.

7. Relling MV, Klein TE. CPIC: Clinical Pharmacogenetics Implementation Consortium of the Pharmacogenomics Research Network. Clin Pharmacol Ther. 2011;89(3):464-67.

8. Haga SB, LaPointe NM. The potential impact of pharmacogenetic testing on medication adherence. Pharmacogenomics J. 2013;13(6):481-83.

9. Barnett MJ, Frank J, Wehring H, et al. Analysis of pharmacist-provided medication therapy management (MTM) services in community pharmacies over 7 years. J Manag Care Pharm. 2009;15(1):18-31. Available at: http:// www.amcp.org/data/jmcp/018-031.pdf.

10. Touchette DR, Masica AL, Dolor RJ, et al. Safety-focused medication therapy management: a randomized controlled trial. J Am Pharm Assoc (2003). 2012;52(5):603-12.

11. American Pharmacists Association; National Association of Chain Drug Stores Foundation. Medication therapy management in pharmacy practice: core elements of an MTM service model (version 2.0). J Am Pharm Assoc (2003). 2008;48(3):341-53.

12. Centers for Medicare \& Medicaid Services. Medicare program; Medicare prescription drug benefit; final rule. 42 CFR Parts 400, 403, 411, 417, and 423. Federal Register. 2005;70(18):4193-585. Available at: http://www.gpo. gov/fdsys/pkg/FR-2005-01-28/pdf/FR-2005-01-28.pdf. Accessed February $14,2015$.

13. Rucker NL. Medicare Part D's medication therapy management: shifting from neutral to drive. Insight on the Issues 64. AARP Public Policy Institute. June 2012. Available at: http://www.aarp.org/content/dam/aarp/research/ public_policy_institute/health/medicare-part-d-shifting-from-neutral-todrive-insight-AARP-ppi-health.pdf. Accessed February 14, 2015

14. Centers for Medicare \& Medicaid Services. 2013 Medicare Part D medication therapy management (MTM) programs: fact sheet summary of 2013 MTM programs. September 12, 2013. Available at: http://www.cms. gov/Medicare/Prescription-Drug-Coverage/PrescriptionDrugCovContra/ Downloads/CY2013-MTM-Fact-Sheet.pdf. Accessed February 14, 2015. 
15. U.S. Food and Drug Administration. Table of pharmacogenomic biomarkers in drug labels. Updated August 18, 2014. Available at: http:// www.fda.gov/Drugs/ScienceResearch/ResearchAreas/Pharmacogenetics/ ucm083378.htm. Accessed February 14, 2015.

16. Grice GR, Seaton TL, Woodland AM, McLeod HL. Defining the opportunity for pharmacogenetic intervention in primary care. Pharmacogenomics. 2006;7(1):61-65.

17. Martin MA, Hoffman JM, Freimuth RR, et al. Clinical Pharmacogenetics Implementation Consortium (CPIC) guidelines for HLA-B genotype and abacavir dosing: 2014 update. Clin Pharmacol Ther. 2014;95(5):499-500.

18. Saag M, Balu R, Phillips E, et al. High sensitivity of human leukocyte antigen-b*5701 as a marker for immunologically confirmed abacavir hypersensitivity in white and black patients. Clin Infect Dis. 2008;46(7):1111-18.

19. Mallal S, Nolan D, Witt C, et al. Association between presence of HLAB*5701, HLA-DR7, and HLA-DQ3 and hypersensitivity to HIV-1 reversetranscriptase inhibitor abacavir. Lancet. 2002;359(9308):727-32.

20. Crews KR, Gaedigk A, Dunnenberger HM, et al. Clinical Pharmacogenetics Implementation Consortium guidelines for cytochrome P450 2D6 genotype and codeine therapy: 2014 update. Clin Pharmacol Ther. 2014;95(4):376-82.

21. Kelly PA. Pharmacogenomics: why standard codeine doses can have serious toxicities or no therapeutic effect. Oncol Nurs Forum. 2013;40(4):322-24.

22. Prows CA, Zhang X, Huth MM, et al. Codeine-related adverse drug reactions in children following tonsillectomy: a prospective study. Laryngoscope. 2014;124(5):1242-50.

23. Anderson JL, Horne BD, Stevens SM, et al. A randomized and clinical effectiveness trial comparing two pharmacogenetic algorithms and standard care for individualizing warfarin dosing (CoumaGen-II). Circulation. 2012;125(16):1997-2005

24. Pirmohamed M, Burnside G, Eriksson N, et al. A randomized trial of genotype-guided dosing of warfarin. N Engl J Med. 2013;369(24):2294-303.

25. Kimmel SE, French B, Kasner SE, et al. A pharmacogenetic versus a clinical algorithm for warfarin dosing. N Engl J Med. 2013;369(24):2283-93.

26. Weitzel KW, Elsey AR, Langaee TY, et al. Clinical pharmacogenetics implementation: approaches, successes, and challenges. Am J Med Genet C Semin Med Genet. 2014;166C(1):56-67.

27. Haga SB, Moaddeb J. Comparison of delivery strategies for pharmacogenetic testing services. Pharmacogenet Genomics. 2014;24(3):139-45.

28. Hoffman JM, Haidar CE, Wilkinson MR, et al. PG4KDS: a model for the clinical implementation of pre-emptive pharmacogenetics. Am J Med Genet C Semin Med Genet. 2014;166C(1):45-55.

29. Gamazon ER, Skol AD, Perera MA. The limits of genome-wide methods for pharmacogenomic testing. Pharmacogenet Genomics. 2012;22(4):261-72.

30. Thomas RE, Chau SB. The AmpliChip: a review of its analytic and clinical validity and clinical utility. Curr Drug Saf. 2014 Apr 28 [Epub ahead of print].

31. Ma JD, Lee KC, Kuo GM. Clinical application of pharmacogenomics. J Pharm Pract. 2012;25(4):417-27.

32. Scott SA. Clinical pharmacogenomics: opportunities and challenges at point of care. Clin Pharmacol Ther. 2013;93(1):33-35.

33. Beatty SJ, McCormick KM, Beale DJ, et al. Current trends in outpatient pharmacy services and billing. J Am Pharm Assoc (2003). 2012;52(2):154-60.

34. Bailey JE, Pope RA, Elliott EC, Wan JY, Waters TM, Frisse ME. Health information exchange reduces repeated diagnostic imaging for back pain. Ann Emerg Med. 2013;62(1):16-24.

35. Bailey JE, Wan JY, Mabry LM, et al. Does health information exchange reduce unnecessary neuroimaging and improve quality of headache care in the emergency department? J Gen Intern Med. 2013;28(2):176-83.

36. Witry MJ, Doucette WR. Obtaining patient test results from clinical laboratories: a survey of state law for pharmacists. J Am Pharm Assoc (2003). 2009;49(3):423-26.
37. Dimitropoulos L, Patel V, Scheffler SA, Posnack S. Public attitudes toward health information exchange: perceived benefits and concerns. Am J Manag Care. 2011;17(12 Spec No.):SP111-16.

38. O'Donnell HC, Patel V, Kern LM, et al. Healthcare consumers' attitudes towards physician and personal use of health information exchange. J Gen Intern Med. 2011;26(9):1019-26.

39. McKnight AG, Thomason AR. Pharmacists' advancing roles in drug and disease management: a review of states' legislation. J Am Pharm Assoc (2003). 2009;49(4):554-58.

40. Punekar Y, Lin SW, Thomas J 3rd. Progress of pharmacist collaborative practice: status of state laws and regulations and perceived impact of collaborative practice. J Am Pharm Assoc (2003). 2003;43(4):503-10.

41. Weaver K. Collaborative practice agreements vary among the states. American Pharmacists Association. February 19, 2013. Available at: http:// www.pharmacist.com/collaborative-practice-agreements-vary-among-states. Accessed February 15, 2015.

42. Council on Credentialing in Pharmacy, Albanese NP, Rouse MJ. Scope of contemporary pharmacy practice: roles, responsibilities, and functions of pharmacists and pharmacy technicians. J Am Pharm Assoc (2003). 2010;50(2):e35-69.

43. Zingone MM, Malcolm KE, McCormick SW, Bledsoe KR. Analysis of pharmacist charges for medication therapy management services in an outpatient setting. Am J Health Syst Pharm. 2007;64(17):1827-31.

44. Christensen DB, Roth M, Trygstad T, Byrd J. Evaluation of a pilot medication therapy management project within the North Carolina State Health Plan. J Am Pharm Assoc (2003). 2007;47(4):471-83.

45. Academy of Managed Care Pharmacy. Sound Medication Therapy Management Programs, Version 2.0 with validation study. J Manag Care Pharm. 2008;14(1 Suppl B):S2-44. Available at: http://www.amcp.org/data/ jmcp/JMCPSuppB_Jan08.pdf.

46. Moczygemba LR, Barner JC, Lawson KA, et al. Impact of telephone medication therapy management on medication and health-related problems, medication adherence, and Medicare Part D drug costs: a 6-month follow up. Am J Geriatr Pharmacother. 2011;9(5):328-38.

47. Hassan S, Naboush A, Radbel J, et al. Telephone-based anticoagulation management in the homebound setting: a retrospective observational study. Int J Gen Med. 2013;6:869-75.

48. Lau DT, Stubbings J. Medicare Part D research and policy highlights, 2012: impact and insights. Clin Ther. 2012;34(4):904-14.

49. Moczygemba LR, Barner JC, Brown CM, et al. Patient satisfaction with a pharmacist-provided telephone medication therapy management program. Res Social Adm Pharm. 2010;6(2):143-54.

50. Schiff GD, Klass D, Peterson J, Shah G, Bates DW. Linking laboratory and pharmacy: opportunities for reducing errors and improving care. Arch Intern Med. 2003;163(8):893-900.

51. McMahan R. Operationalizing MTM through the use of health information technology. J Manag Care Pharm. 2008;14(2 Suppl):S18-21. Available at: http://www.amcp.org/data/jmcp/JMCPSupp_March\%2008_S18-S21.pdf.

52. Lauffenburger JC, Balasubramanian A, Farley JF, et al. Completeness of prescription information in US commercial claims databases. Pharmacoepidemiol Drug Saf. 2013;22(8):899-906.

53. Hicks JK, Crews KR, Hoffman JM, et al. A clinician-driven automated system for integration of pharmacogenetic interpretations into an electronic medical record. Clin Pharmacol Ther. 2012;92(5):563-66.

54. U.S. Department of Labor, Bureau of Labor Statistics. Occupational outlook handbook: pharmacists. 2014-15 edition. January 8, 2014. Available at: http:// www.bls.gov/ooh/healthcare/pharmacists.htm. Accessed February 15, 2015.

55. Blake KB, Madhavan SS. Perceived barriers to provision of medication therapy management services (MTMS) and the likelihood of a pharmacist to work in a pharmacy that provides MTMS. Ann Pharmacother. 2010;44(3):424-31. 
56. Accreditation Council for Pharmacy Education. Accreditation standards and guidelines for the Professional Program in Pharmacy leading to the Doctor of Pharmacy Degree. January 15, 2006. Available at: https:// www.acpe-accredit.org/pdf/ACPE_Revised_PharmD_Standards_Adopted_ Jan152006.pdf. Accessed February 15, 2015.

57. Battaglia JN, Kieser MA, Bruskiewitz RH, Pitterle ME, Thorpe JM. An online virtual-patient program to teach pharmacists and pharmacy students how to provide diabetes-specific medication therapy management. Am J Pharm Educ. 2012;76(7):131.

58. Begley KJ, Coover KL, Tilleman JA, Haddad AMR, Augustine SC. Medication therapy management training using case studies and the MirixaPro platform. Am J Pharm Educ. 2011;75(3):49.

59. Eukel HN, Skoy ET, Frenzel JE. Provision of medication therapy management to university faculty and staff members by third-year pharmacy students. Am J Pharm Educ. 2010;74(10):182.

60. Ryder PT, Meyerson BE, Coy KC, von Hippel CD. Pharmacists' perspectives on HIV testing in community pharmacies. J Am Pharm Assoc (2003). 2013;53(6):595-600

61. Moczygemba LR, Goode JV, Silvester JA, Matzke GR. Pharmacy practice in Virginia in 2011. Ann Pharmacother. 2012;46(4):S13-26.

62. McCullough KB, Formea CM, Berg KD, et al. Assessment of the pharmacogenomics educational needs of pharmacists. Am J Pharm Educ. 2011;75(3):51.

63. Murphy JE, Green JS, Adams LA, Squire RB, Kuo GM, McKay A. Pharmacogenomics in the curricula of colleges and schools of pharmacy in the United States. Am J Pharm Educ. 2010;74(1):7.

64. Krynetskiy E, Lee Calligaro I. Introducing pharmacy students to pharmacogenomic analysis. Am J Pharm Educ. 2009;73(4):71.

65. Lee KC, Ma JD, Hudmon KS, Kuo GM. A train-the-trainer approach to a shared pharmacogenomics curriculum for US colleges and schools of pharmacy. Am J Pharm Educ. 2012;76(10):193.

66. Drozda K, Labinov Y, Jiang R, et al. A pharmacogenetics service experience for pharmacy students, residents, and fellows. Am J Pharm Educ. 2013;77(8):175.

67. Formea CM, Nicholson WT, McCullough KB, et al. Development and evaluation of a pharmacogenomics educational program for pharmacists. Am J Pharm Educ. 2013;77(1):10.

68. Haga SB, Burke W, Ginsburg GS, Mills R, Agans R. Primary care physicians' knowledge of and experience with pharmacogenetic testing.

Clin Genet. 2012;82(4):388-94.

69. Selkirk CG, Weissman SM, Anderson A, Hulick PJ. Physicians' preparedness for integration of genomic and pharmacogenetic testing into practice within a major healthcare system. Genet Test Mol Biomarkers. 2013;17(3):219-25.

70. Stanek EJ, Sanders CL, Taber KA, et al. Adoption of pharmacogenomic testing by US physicians: results of a nationwide survey. Clin Pharmacol Ther 2012;91(3):450-58.

71. Green JS, O'Brien TJ, Chiappinelli VA, Harralson AF. Pharmacogenomics instruction in US and Canadian medical schools: implications for personalized medicine. Pharmacogenomics. 2010;11(9):1331-40.

72. American Association of Colleges of Nursing. The essentials of baccalaureate education for professional nursing practice. October 20, 2008. Available at: http://www.aacn.nche.edu/Education/pdf/BaccEssentials08.pdf. Accessed February 15, 2015

73. Greco KE, Tinley S, Seibert D. Essential Genetic and Genomic Competencies for Nurses with Graduate Degrees. Silver Spring, MD: American Nurses Association and International Society of Nurses in Genetics; 2012.
74. Jenkins JF, Calzone K. Essentials of Genetic and Genomic Nursing: Competencies, Curricula Guidelines, and Outcome Indicators. 2nd ed. Silver Spring, MD: American Nurses Association; 2009.

75. Thompson HJ, Brooks MV. Genetics and genomics in nursing: evaluating essentials implementation. Nurse Educ Today. 2011;31(6):623-27.

76. Evans BJ. Finding a liability-free space in which personalized medicine can bloom. Clin Pharmacol Ther. 2007;82(4):461-65.

77. Prebula RJ. The promise of personalized medicine: regulatory controls and tort influences in the context of personalized risks and benefits. J Contemp Health Law Policy. 2010;26(2):343-72.

78. Moore JJ, Matlock AG. Shared liability? Consultants, pharmacists, and the emergency physician: legal cases and caveats. J Emerg Med. 2014:46(5):612-16.

79. Hornish ML. Just what the doctor ordered—or was it? Missouri pharmacists' duty of care in the 21st century. Missouri L Rev. 2000;65(1075):1085.

80. Zierler-Brown S, Brown TR, Chen D, Blackburn RW. Clinical documentation for patient care: models, concepts, and liability considerations for pharmacists. Am J Health Syst Pharm. 2007;64(17):1851-58.

81. Donovan MJ. Legal issues stemming from the advancement of pharmacogenomics. UCLA J Law Technol. 2010;14(1):35. Available at: http:// www.lawtechjournal.com/articles/2010/01_100915_donovan.pdf. Accessed February 15, 2015.

82. Lounsbery JL, Green CG, Bennett MS, Pedersen CA. Evaluation of pharmacists' barriers to the implementation of medication therapy management services. J Am Pharm Assoc (2003). 2009;49(1):51-58.

83. Moczygemba LR, Barner JC, Gabrillo ER, Godley PJ. Development and implementation of a telephone medication therapy management program for Medicare beneficiaries. Am J Health Syst Pharm. 2008;65(17):1655-60.

84. Law AV, Okamoto MP, Brock K. Ready, willing, and able to provide MTM services? A survey of community pharmacists in the USA. Res Social Adm Pharm. 2009;5(4):376-81.

85. Lloyd KB, Evans RL. Reimbursement model for pharmacist-directed medication therapy management. J Am Pharm Assoc (2003). 2012;52(2):161-69.

86. Trapskin K, Johnson C, Cory P, Sorum S, Decker C. Forging a novel provider and payer partnership in Wisconsin to compensate pharmacists for quality-driven pharmacy and medication therapy management services. J Am Pharm Assoc (2003). 2009;49(5):642-51.

87. Scott MA, Hitch WJ, Wilson CG, Lugo AM. Billing for pharmacists' cognitive services in physicians' offices: multiple methods of reimbursement J Am Pharm Assoc (2003). 2012;52(2):175-80.

88. Traynor K. CMS chief affirms incident-to billing for pharmacists is allowed. Am J Health Syst Pharm. 2014;71(12):977-78.

89. Boyd ST, Boyd LC, Zillich AJ. Medication therapy management survey of the prescription drug plans. J Am Pharm Assoc (2003). 2006;46(6):692-99.

90. Watkins JL, Landgraf A, Barnett CM, Michaud L. Evaluation of pharmacist-provided medication therapy management services in an oncology ambulatory setting. J Am Pharm Assoc (2003). 2012;52(2):170-74.

91. Albada A, van Dulmen S, Bensing JM, Ausems MG. Effects of a pre-visit educational website on information recall and needs fulfilment in breast cancer genetic counselling, a randomized controlled trial. Breast Cancer Res. 2012;14(2):R37.

92. Zhang S, Doucette WR, Urmie JM, Xie Y, Brooks JM. Factors associated with independent pharmacy owners' satisfaction with Medicare Part D contracts. Res Social Adm Pharm. 2010;6(2):121-29. 